\title{
Xerostomia, Xerogenic Medications and Food Avoidances in Selected Geriatric Groups
}

\author{
W. J. Loesche, DMD, PbD, ${ }^{* \dagger} J$. Bromberg, PhD, ${ }^{\ddagger}$ M. S. Terpenning, MD, ${ }^{\dagger \mathrm{S}}$ W. A. Bretz, DrPH, \\ B. L. Dominguez, $M S,{ }^{, S}$ N. S. Grossman, MA," and S. E. Langmore, PhD"s
}

OBJECTIVE: To study the relationship between complaints of xerostomia and salivary performance and food avoidances in four geriatric groups chosen to reflect a broad spectrum of individuals along the health-disease continuum. To determine whether xerogenic medications taken by these individuals could be associated with either complaints of xerostomia or with food avoidances.

DESIGN: Cross-sectional survey. Clinical examinations and interview.

SETTING: A VA dental clinic and a retirement home.

PATIENTS AND OTHER PARTICIPANTS: Subjects were 529 individuals older than 56 years of age, living both in institutions and in the community (average age 70 years). Two hundred eight persons were recruited from a VA Dental Clinic, 114 from a residential retirement home, and 132 from a nursing/long-term-care facility; 75 were from an acute care ward and had a diagnosis of a cerebral vascular accident or other neurological condition.

OUTCOME MEASURES: Prevalence of xerostomia, dental morbidity, salivary flow, and food avoidances.

RESULTS: About $72 \%$ of the subjects experienced xerostomia sometime during the day. Stimulated salivary flow was found to be significantly lower in individuals who complained of xerostomia than in those who did not. Fifty-five percent of participants reported using one or more xerogenic medications, with an $86 \%$ prevalence in the nursing/longterm-care facility. Individuals with xerostomia had difficulty in chewing and in starting a swallow and were significantly more likely to avoid crunchy foods such as vegetables, dry foods such as bread, and sticky foods such as peanut butter in their diets. Specific medications such as the inhalants ipratropium and triamcinolone and the systemic agents oxybutynin and triazolam could be statistically associated with xerostomia and/or low salivary flow, and/or specific food avoidances.

\footnotetext{
From the "University of Michigan School of Dentistry, tUniversity of Michigan School of Medicine, ¥University of Michigan Department of Biostatistics School of Public Health and SAnn Arbor Veterans Affairs Medical Center Ann Arbor, Michigan.

This investigation is supported by USPH Research Grant DE-09142 from the National Institute of Dental Research, and IP30-AG-008808 from the National Institutes of Health, Bethesda, Maryland.

Address correspondence to Walter J. Loesche, DMD, PhD, University of Michigan School of Dentistry, 1011 N. University, Ann Arbor, Michigan 48109-1078.
}

CONCLUSION: Xerostomia apparently affects the ability to chew and start a swallow. This leads to avoidance of certain foods, which raises the possibility that xerostomia could contribute to undernutrition in older persons. The topically applied ipratropium and triamcinolone and the systemic agents amitriptyline, oxybutynin and triazolam could be statistically associated with one or more complaints of xerostomia. J Am Geriatr Soc 43:401-407, 190.

$\mathrm{P}$ oor dental health, as measured by the number of missing teeth and/or the number of decayed or periodontally diseased teeth, can affect dietary choices with resultant adverse nutritional consequences. ${ }^{1}$ This problem is potentially important in older persons, where the prevalence of oral/ dental problems is high. ${ }^{2-6}$ Sullivan and colleagues have shown that poor oral hygiene, ${ }^{7}$ xerostomia, and the inability to chew, among other oral conditions, were the best predictors of significant involuntary weight loss in the previous year among a population of frail older persons. In related studies, weight loss in the year before admission was one of the strongest predictors of subsequent in-hospital morbidity and mortality, ${ }^{8}$ and involuntary weight loss was a strong predictor of 1-year postdischarge mortality. ${ }^{9}$

Xerostomia is a common complaint of older people and is usually associated with reduced salivary flow. ${ }^{10-12}$ While some cases of xerostomia are related to auto-immune diseases such as Sjogren's syndrome, ${ }^{13}$ and others are secondary to irradiation treatment of oral neoplasms, ${ }^{14}$ the majority of the cases appear to be related to the usage of certain medications. ${ }^{15-18}$ More than 400 medications have been cited as xerostomia-inducing or xerogenic drugs, ${ }^{19}$ but with the exception of tricyclic antidepressants, ${ }^{20}$ anticholinergic agents, certain psychotrophic medications and antihistamines, and possibly diuretics, ${ }^{21}$ most of the evidence linking a particular medication with xerostomia is anecdotal. In addition, several studies have shown that the number of medications used by the individual per day, regardless of whether they are xerogenic, can be associated with xerostomia. ${ }^{16,22,23}$

The aim of the present investigation was to study the prevalence of complaints of xerostomia in four geriatric groups chosen to reflect a broad spectrum of individuals along the health-disease continuum (Loesche et al., unpublished data, 1994). We then determined whether xerostomia could be associated with reduced salivary performance and with the avoidance of various types of food. We also investigated which xerogenic medications taken by these individuals 
could be associated with either complaints of xerostomia or with avoidance of certain types of food.

\section{MATERIALS AND METHODS}

\section{Sample Population}

Subjects/patients were chosen with the intention of having groups with different medical backgrounds. All participants were at least 56 years of age (average age was 70 years) and signed a consent form approved by an institutional review board at both the University of Michigan School of Dentistry and the Ann Arbor Veterans Affairs Medical Center. The characteristics of these populations have been described elsewhere and will be briefly summarized (Loesche et al., unpublished data, 1994).

\section{Independent Living Groups}

This group consisted of 208 individuals recruited from the VA Dental Clinic and 114 individuals recruited from either the Glacier Hills Retirement Center, Ann Arbor, Michigan or from the Turner Geriatric Clinic at the University of Michigan Medical Center, Ann Arbor, Michigan. Ninetyfour percent of the VA subjects were male, and $94 \%$ were white. Their average age was 67.8 years \pm 5.1 years. Thirty percent of the non-VA subjects were male and $98 \%$ were white. Their average age was $78 \pm 8.5$ years. Because of these differences in age and gender, two separate independent living groups were established (Loesche et al., unpublished data, 1994).

\section{Dependent Living Groups}

The nursing home group consisted of 122 residents of the long-term-care facility of the VA Hospital and 10 residents of the Glacier Hills Nursing Home. Ninety-two percent of the Nursing Home group were males, and $89 \%$ were white. Their average age was $70 \pm 7.2$ years.

The hospitalized group consisted of 75 VA patients, who had been admitted to the acute care unit with a diagnosis of a cerebral vascular accident or other neurological condition. About $90 \%$ of these individuals had been in an independent living status before their admission. One hundred percent of the Hospitalized group were males, and $81 \%$ were white. Their average age was $67 \pm 6.0$ years.

\section{Questionnaire}

All participants were interviewed by trained interviewers who used a structured questionnaire to elicit information about demographic characteristics, medical and dental history, use of medications, complaints of xerostomia, ${ }^{24}$ and various food avoidances (questionnaire available upon request). The questionnaire was pretested for comprehension in a subsample of older individuals. In a few cases, mostly in the Hospitalized group, the information was obtained with the assistance of a relative. The interview lasted from 1 to $1 \frac{1 / 2}{2}$ hours, and provided detailed information relative to the subject's eating habits, food and liquid preferences, avoidance of food types, oral hygiene habits, complaints of a dry mouth (xerostomia), swallowing complaints, medical history, and usage of prescription medications. We asked the subjects questions regarding the time of the day in which they experienced a dry mouth and then questions regarding the amount of saliva they perceived. The questions on xerostomia were again asked by the dentist when the subjects had their dental examination. Only those subjects who answered yes to the xerostomia questions on both occasions were considered as having xerostomia for our analysis.

For VA participants, the reported current use of medications was compared with the computerized pharmacy records maintained by the Ann Arbor VA Medical Center. For the non-VA participants the individual was asked to bring all medications currently being taken, to the interview, and only these medications were recorded on our forms. Medications were identified as xerogenic using the PDR Drug Interactions/ Side Effects/Indications software program version 2.0 (Physician's Desk Reference, Medical Economical Data Inc., Montvale NJ).

\section{Dental Examination}

All VA patients were examined by the same clinician/ dental assistant team at the VA dental facility. All non-VA patients were examined by a second clinician/dental hygienist team using the dental facility at the Glacier Hills Retirement Center. Both teams were initially calibrated by the same individual (WB) and were recalibrated semiannually. The number of teeth that were present and the number of decayed/missing/filled teeth and surfaces (DMF teeth, DMF surfaces) were recorded on standardized forms. ${ }^{6}$ The presence of any fixed or removable prostheses, dentures or implants was recorded. Edentulousness was defined for our analysis as the absence of natural teeth and did not take into account whether dentures were present. Approximately $90 \%$ of the edentulous individuals had dentures available.

\section{Saliva}

Whole saliva was stimulated by swabbing the tongue with a $2 \%$ citric acid solution three times at 30 -second intervals. ${ }^{13}$ During the next minute, the patients swallowed the first flow of saliva containing the citric acid. Thereafter the stimulated saliva was collected over a 5 -minute period by asking the patients to tilt their head forward and to spit their saliva into a graduated, preweighed, conical tube. If the patient was unable to provide about $1 \mathrm{~mL}$ of saliva after 5 minutes, he/she was given a default value of $<0.2 \mathrm{~mL} / \mathrm{min}$. All VA Hospitalized patients had their saliva collected by a suction procedure, ${ }^{25}$ as it was not possible for them to spit. The amount of saliva, as determined gravimetrically, the length of collection, and the time of day of the collection were also recorded. The minor salivary gland output was measured as the degree of wetness present in specially prepared standardized cellulose strips. ${ }^{26}$ These strips were individually placed on the hard palate, the buccal mucosa, and the inside lip and were allowed to absorb moisture for 30 seconds. The wetness was measured using a Periotron ${ }^{\mathrm{TM}}$ instrument that was calibrated each day against a known volume of serum. The findings were reported as $\mu \mathrm{L} / \mathrm{min}$ for each location, and the sum of the three intraoral locations was reported as the minor salivary gland output.

\section{Statistical Analysis}

If the attained probability of the overall comparisons for any given parameter was less than $P=.05$, then pair-wise comparisons were performed using Fisher's Exact test for categorical variables at two levels. The large number of comparisons being made caused us to accept a $P<.01$ as being significant for the pairwise comparisons. Significance in those parts of Tables 2 to 4 that illustrate discrete $2 \times 2$ 
associations was obtained using Fisher's Exact Test. The underlying differences between groups for the continuous variables in Tables 3 and 4 were found using the nonparametric Wilcoxon rank-sum test. This nonparametric test was used because of the lack of a normal distribution in the parameters under investigation.

\section{RESULTS}

There were no significant differences between the four groups when complaints of xerostomia were compared (Table 1). About $72 \%$ of the subjects experienced xerostomia at some time during the day, with about $46 \%$ reporting this complaint either in the morning or at night. Complaints in the evening were significantly higher for the Hospitalized patients. Only $13 \%$ of the participants had complaints when eating (Table 1). There was no effect of age on the complaint of xerostomia; both complainers and noncomplainers averaged 70.3 to 70.7 years in age. There was no relationship between edentulousness and xerostomia, as $30 \%$ of both the complainers and noncomplainers were edentulous. There was no obvious effect of gender because the mostly female, non-VA subjects did not have a significantly lower level of complaints than did the male VA subjects. Because of these similarities, the four groups were combined for the subsequent analysis of xerostomia.

A complaint of xerostomia at any time of the day was associated with a significant reduction in both stimulated salivary flow $(0.69 \pm 0.35 \mathrm{~mL} / \mathrm{min}$ vs $0.58 \pm 0.31 \mathrm{~mL} / \mathrm{min}$, $P<.001$ Wilcoxon rank sum test), and in minor salivary gland output $(5.8 \pm 2.3 \mu \mathrm{L} / \mathrm{min}$ vs $5.3 \pm 2.5 \mu \mathrm{L} / \mathrm{min}$, $P=.03$ ). A complaint of xerostomia while eating was associated with the greatest reduction in stimulated salivary flow $(0.63 \pm 0.33 \mathrm{~mL} / \mathrm{min}$ vs $0.41 \pm 0.22 \mathrm{~mL} / \mathrm{min})$, but with the smallest reduction in minor salivary gland output $(5.5 \mu \mathrm{L}$ $\min$ vs $5.1 \mu \mathrm{L} / \mathrm{min}$ ). We chose "xerostomia in the morning" as the complaint of reference for all subsequent analysis because this complaint was the most frequently reported and because the magnitude of difference between complainers and noncomplainers in regard to stimulated salivary flow $(0.12 \mathrm{~mL} / \mathrm{min})$, and minor salivary gland output $(0.9 \mu \mathrm{L} /$ $\mathrm{min}$ ), was the greatest in individuals with this complaint.

We determined whether this complaint of xerostomia in the morning could be associated with oral problems relating to dryness. The individuals who complained of xerostomia were 14.1 times more likely to state that their cheeks stuck to their teeth (Table 2). These individuals were significantly more likely to report that food sticks in their throat and that they had difficulty in chewing, in starting a swallow, and in swallowing (Table 2). They were 6.4 times more likely to report that they had too little saliva, and their mouths were 5.2 times more likely to be dry when eating. Perhaps to compensate for this dryness, they were 2.1 times more likely to report that they sip liquids to help them swallow dry foods.

These findings suggested that an individual with a complaint of xerostomia might have problems eating because of these difficulties associated with chewing and swallowing. We asked all subjects whether there were certain foods that $\mathrm{s} /$ he avoided in their diets. Thirty-one percent of the individuals with a complaint of "xerostomia in the morning" stated that they avoided one or more food types, a prevalence that was significantly higher than the response rate of $18 \%$ reported by people without the complaint (Table 2 ). The individuals who complained of xerostomia, relative to the nonxerostomic individuals, were significantly more likely to avoid crunchy foods such as carrots and sticky foods such as peanut butter. There was also a tendency to avoid dry foods such as bread.

We determined whether the complaint of xerostomia could be associated with the usage of putative xerogenic medications. About 46 to $48 \%$ of the Independent Living subjects, $55 \%$ of the Hospitalized patients, but $86 \%$ of the Nursing Home patients used one or more xerogenic medications. The higher frequency of usage in the Nursing Home patients was significant when compared with the other groups, i.e., $P<.001$. However, despite this higher usage of putative xerogenic medications in the nursing home, these individuals did not have a significantly higher prevalence of xerostomic complaints (Table 1). The individuals who used xerogenic medications were 2.1 times more likely to have a complaint of xerostomia in the morning, than individuals who did not use xerogenic medications $(P<0.001)$. These individuals also had significantly less stimulated salivary flow, but there was no apparent effect of the usage of xerogenic medications on the minor salivary gland output (Table 3). Individuals who used xerogenic medications were 2.5 times more likely to be edentulous and, among the dentate individuals, were 2.7 times more likely to have fewer than 10 teeth, compared with those individuals who did not use xerogenic medications (Table 3 ).

Table 1. Frequency of Complaints of Xerostomia Among the Various Geriatric Groups

\begin{tabular}{|c|c|c|c|c|c|}
\hline \multirow[b]{2}{*}{ Complaint of Xerostomia } & \multirow{2}{*}{$\begin{array}{c}\text { All } \\
\text { Subjects } \\
n=529\end{array}$} & \multicolumn{2}{|c|}{ Independent Living } & \multicolumn{2}{|c|}{ Dependent Living } \\
\hline & & $\begin{array}{c}\text { non-VA } \\
n=114\end{array}$ & $\begin{array}{c}\text { VA } \\
n=208\end{array}$ & $\begin{array}{l}\text { Nursing Home } \\
n=132\end{array}$ & $\begin{array}{l}\text { Hospitalized } \\
\quad n=75\end{array}$ \\
\hline Any time ${ }^{\dagger}$ & $72 \%{ }^{\star}$ & $68 \% \%^{*}$ & $72 \% *$ & $71 \%{ }^{*}$ & $82 \%{ }^{*}$ \\
\hline In morning & 46 & 48 & 40 & 51 & 54 \\
\hline In afternoon & 31 & 27 & 28 & 33 & 39 \\
\hline In evening ${ }^{*}$ & 32 & 27 & 26 & 35 & $49^{\ddagger}$ \\
\hline At night & 45 & 43 & 42 & 49 & 50 \\
\hline When eating & 13 & 8 & 13 & 15 & 18 \\
\hline
\end{tabular}

*Proportion of individuals in each group who gave a positive response for complaint.

tAny time would include individuals who had one or more complaints related to the five temporal periods listed.

†Overall difference is significant, $P=\mathbf{0 . 0 0 4}$, due primarily to high proportion of complaints in hospitalization patients relative to both independent living groups. 
Table 2. Relationship Between Complaints of Xerostomia in the Morning and Complaints Relative to Oral Dryness and Eating and Salivary Hypofunctions

\begin{tabular}{|c|c|c|c|c|}
\hline & \multicolumn{2}{|c|}{$\begin{array}{l}\text { Complaints of Xerostomia } \\
\text { in Morning }\end{array}$} & \multirow[b]{2}{*}{ Significance $^{\dagger}$} & \multirow{2}{*}{$\begin{array}{l}\text { Odds Ratio } \\
(95 \% \mathrm{Cl})\end{array}$} \\
\hline & No $(281)^{*}$ & Yes (242) & & \\
\hline \multicolumn{5}{|l|}{ Oral dryness } \\
\hline Cheeks stick to teeth & $1.1 \%^{\ddagger}$ & $13.5 \%$ & $<0.001$ & $14.1(4.2,46.7)$ \\
\hline Food stick in throat & 17.3 & 34.2 & $<0.001$ & $2.5(1.6,3.7)$ \\
\hline \multicolumn{5}{|l|}{ Difficulty in } \\
\hline chewing & 12.2 & 27.2 & $<0.001$ & $2.7(1.7,4.3)$ \\
\hline starting a swallow & 8.7 & 18.9 & $<0.001$ & $2.4(1.4,4.2)$ \\
\hline in swallowing $\$$ & 19.0 & 34.8 & $<0.001$ & $2.3(1.5,3.4)$ \\
\hline \multicolumn{5}{|c|}{$\begin{array}{l}\text { Subjective measures of salivary } \\
\text { hypofunction }\end{array}$} \\
\hline Sip liquids $\$$ & 26.8 & 43.9 & $<0.001$ & $2.1(1.5,3.1)$ \\
\hline Mouth dry when eating $\$$ & 5.1 & 21.8 & $<0.001$ & $5.2(2.8,9.7)$ \\
\hline Is saliva too littles & 7.9 & 35.6 & $<0.001$ & $6.4(3.9,10.7)$ \\
\hline \multicolumn{5}{|l|}{ Types of foods avoided } \\
\hline Any food & $17.7 \% \neq$ & $31.5 \%^{\ddagger}$ & $<0.001$ & $2.1(1.4,3.2)$ \\
\hline Chewy (beef)" & 12.3 & 17.3 & NS & \\
\hline Crunchy (carrot) & 9.4 & 17.7 & 0.006 & $2.1(1.2,3.5)$ \\
\hline Dry (bread) & 5.4 & 10.0 & 0.065 & $2.0(1.0,3.8)$ \\
\hline Crumbly (Cake) & 3.6 & 6.3 & NS & \\
\hline Sticky (peanut butter) & 2.9 & 8.0 & 0.016 & $2.9(1.2,6.8)$ \\
\hline
\end{tabular}

* Number of subjects in each response group.

tSignificance - Fisher's Exact test - 2 tail.

¥Percentage of subjects who responded yes to question.

SQuestions related to salivary hypofunction. See ref. 25.

"Example of food type explained to patient when asking question in food avoidance.

Table 3. Relationship Between Usage of Xerogenic Medications and Salivary Function and Dental Status

\begin{tabular}{lccccc}
\hline $\begin{array}{c}\text { Usage of Xerogenic } \\
\text { Medications }\end{array}$ & $\begin{array}{c}\text { No. of } \\
\text { Subjects }\end{array}$ & $\begin{array}{c}\text { Simulated } \\
\text { Salivary Flow } \\
\mathrm{mL} / \mathrm{min}\end{array}$ & $\begin{array}{c}\text { Minor Salivary } \\
\text { Gland Output } \\
\mu L / \text { min. }\end{array}$ & $\begin{array}{c}\% \\
\text { Edentulous }\end{array}$ & $\begin{array}{c}\% \text { Dentate } \\
\geq 10 \text { teeth }\end{array}$ \\
\hline No & 222 & $0.64 \pm 0.34$ & $5.2 \pm 2.3$ & 20 & $72 \%$ \\
Yes & 307 & $0.58 \pm 0.32$ & $5.5 \pm 2.6$ & 37 & $49 \%$ \\
Significance & & $P=0.025^{*}$ & NS & $P<.001^{\dagger}$ & $P<.001^{\dagger}$ \\
$\begin{array}{l}\text { Odds Ratio (95\% } \\
\text { confidence interval) }\end{array}$ & & & & $2.5(1.6,3.7)$ & $2.7(1.8,4.0)$ \\
\hline
\end{tabular}

-Wilcoxon rank-sum test.

'Fisher's Exact Test.

We next examined the relationship between the reported usage of individual putative xerogenic medications with the complaints of xerostomia and with the measured salivary parameters. The 20 xerogenic medications used most frequently by these subjects were examined for their association with any complaint of xerostomia or with any problems of salivary gland performance. The three most frequently prescribed putative xerogenic medications, diltiazem ( $\mathrm{n}=55$ subjects), diphenhydramine ( $n=49$ subjects), and triamterene/hydrochlorothiazide ( $\mathrm{n}=39$ subjects) could not be associated with any complaint of xerostomia or with any form of reduced salivary gland performance. Likewise, the usage of verapamil ( $n=20$ subjects), timolol $(n=21$ subjects), hydroxyzine ( $n=12$ subjects), clonidine ( $n=11$ subjects), metoprolol ( $n=11$ subjects), guaifenesin ( $n=10$ subjects), and thiethylperazine ( $\mathrm{n}=9$ subjects) could not be associated with any complaint of xerostomia or with reduced salivary flow. However, with these latter medications the number of subjects may have been too small to draw any conclusions.

Seven medications, ipratropium (Atrovent), triamcinolone (Azmacort), oxybutynin (Ditropan), amitriptyline (Elavil), triazolam (Halcion), sucralfate (Carafate), and ibuprofen (Motrin) could be significantly associated with complaints of xerostomia at one or more times during the day (Table 4). The individuals who used ipratropium were 15 times more likely to report any complaint of xerostomia than were individuals who did not use this bronchodilator. Despite this strong association with complaints of xerostomia, ipratropium was not associated with a reduced stimulated 
Table 4. Relationship Between Usage of Certain Xerogenic Medications and Complaints of Xerostomia, and Salivary Parameters

\begin{tabular}{|c|c|c|c|c|c|c|c|c|c|c|c|c|}
\hline \multirow{3}{*}{$\begin{array}{c}\text { Xerogenic } \\
\text { Medication }(\mathbb{N})\end{array}$} & \multicolumn{8}{|c|}{ Xerostomia } & \multicolumn{4}{|c|}{ Salivary Parameters } \\
\hline & \multicolumn{2}{|c|}{ Any Time } & \multicolumn{2}{|c|}{ In Morning } & \multicolumn{2}{|c|}{$\begin{array}{l}\text { At Night/in } \\
\text { evening }\end{array}$} & \multicolumn{2}{|c|}{$\begin{array}{l}\text { Dry while } \\
\text { eating }\end{array}$} & \multicolumn{2}{|c|}{$\begin{array}{l}\text { Too Little } \\
\text { (Subjective) }\end{array}$} & \multirow{2}{*}{$\begin{array}{c}\begin{array}{c}\text { Stimulate } \\
\mathrm{d}\end{array} \\
\text { Sig(P)\| }\end{array}$} & \multirow{2}{*}{$\begin{array}{l}\text { MSGO }^{\$} \\
\text { Sig(P) }\end{array}$} \\
\hline & $\mathrm{OR}^{\dagger}$ & $\overline{\operatorname{Sig}(P)^{\dagger}}$ & OR & $\overline{\operatorname{Sig}(P)}$ & OR & $\operatorname{Sig}(P)$ & OR & $\operatorname{Sig}(P)$ & OR & $\operatorname{Sig}(P)$ & & \\
\hline Ipratropium (36) & 14.9 & $<.001$ & 2.1 & .05 & 2.9 & $<.003$ & 3.2 & .006 & 2.9 & .005 & & $.03 \ddagger$ \\
\hline Triamcinolone (13) & & & 6.4 & .009 & 4.1 & .03 & 3.4 & .06 & 6.2 & .002 & & \\
\hline Oxybutynin (18) & & & 4.1 & .01 & 3.2 & .03 & & & & & & \\
\hline Triazolam (38) & & & & & 2.2 & .03 & & & & & .01 & \\
\hline Amitriptyline (18) & & & & & 2.8 & .04 & & & 4.9 & .001 & .02 & .08 \\
\hline Fluoxetinne (9) & & & & & & & & & & & .02 & \\
\hline Sucralfate (27) & & & & & & & 2.9 & .03 & & & .03 & \\
\hline Ibuprofen (37) & & & & & & & 2.6 & .03 & & & & \\
\hline Transderm-nitro (19) & & & & & & & & & & & & .03 \\
\hline
\end{tabular}

Number of subjects using medication.

'Sig = significance using Fisher's Exact Test; OR = Odds Ratio. All values are significant in that the $95 \%$ confidence interval does not include 1.0 .

${ }^{\ddagger}$ Higher in group taking ipratropium.

$s_{\text {MSGO }}=$ minor salivary gland output.

"Differences between subjects using and not using medication significant using Wilcoxon rank sum test.

salivary flow, and there was actually a significant increase in the minor salivary gland output (Table 4). The patients who used ipratropium were more likely to be edentulous, and if dentate, to have fewer than 10 teeth (data not shown). Individuals who used the other inhalant on this list, triamcinolone, were 6 times more likely to report a complaint of xerostomia in the morning and to state that they had too little saliva (Table 4). There was no observed reduction in either stimulated salivary flow or in the minor salivary gland output. The subjects who used oxybutynin, triazolam, and amitriptyline were significantly more likely to complain of xerostomia in the evening or at night. The usage of sucralfate and ibuprofen were associated with dryness only when eating.

The use of triazolam, amitriptyline, fluoxetine, and sucralfate was associated with a significantly reduced stimulated salivary flow, but with the exception of amitriptyline, there was no effect on the minor salivary gland output (Table 4). Although none of the nine individuals who used fluoxetine had a complaint of xerostomia, there was a significantly lower stimulated salivary flow in these patients. Transdermnitro and, to a lesser extent, amitriptyline were associated with lower minor salivary gland output (Table 4).

We next determined whether any of these 20 putative xerogenic medications could be associated with any reported food avoidances. Individuals using ipratropium were signifcantly more likely to avoid one or more types of food (OR = $2.28, P=.04)$, especially chewy (meats) $(\mathrm{OR}=3.2, P=$ .005 ) and crunchy (carrots) $(O R=2.8, P=.02)$ types of food. The individuals taking amitriptyline were 7 times more likely to avoid chewy foods $(P=.007)$, and those using diphenhydramine were 2.4 times more likely to avoid crunchy foods $(P=.02)$.

\section{DISCUSSION}

The $72 \%$ prevalence of complaints of xerostomia at any time during the day reported by the participants in this investigation (Table 1 ) is higher than the prevalences of 10 to $55 \%$ found by other investigators. ${ }^{10-12,15-18}$ This could re- flect the fact that participants were asked multiple questions about the time of day in which they experienced mouth dryness, were queried about xerostomia on two separate occasions, and that the xerostomia questions were positioned after those questions related to thirst. Our positive xerostomia responses would also have been increased by the inclusion of hospitalized patients with a swallowing problem. Eighty-two percent of these patients reported having a complaint of xerostomia (Table 1), but as they comprised only $14 \%$ of our total population, they alone, could not account for the high prevalence of xerostomia noted.

Xerostomia has been associated with various oral/dental problems, such as an increased prevalence of decay, ${ }^{10,27}$ edentulousness, ${ }^{28}$ and salivary hypofunction. ${ }^{10,24}$ We observed similar associations in that our subjects with complaints of xerostomia had significantly more decayed teeth, (unpublished data), and reduced stimulated whole saliva and minor salivary gland output. Some investigators have found no relationship between complaints of xerostomia and stimulated salivary flow. ${ }^{23,24,29}$ Several investigators have suggested that resting whole saliva production, ${ }^{22,24,28}$ which has a large contribution from the submandibular gland and lesser amounts from the parotid, sublingual and the various minor salivary glands, ${ }^{30,31}$ is the most reliable objective correlate of xerostomia. Resting whole saliva is difficult to measure, especially in the sick and in older persons, and because of this is often not included in investigations of xerostomia. ${ }^{32,33} \mathrm{We}$ have used the minor salivary gland output as a surrogate for resting whole saliva because its collection is simple and reproducible. ${ }^{26}$ Although the minor salivary gland output may only comprise up to $8 \%$ of the resting salivary flow, ${ }^{30,31}$ we found that it was significantly associated with complaints of xerostomia. This suggests that the minor salivary gland output may serve as a surrogate for resting whole saliva in studies involving xerostomia.

Complaints of xerostomia in our subjects could be significantly associated with a positive response to a series of questions that have been shown to significantly correlate with hypofunction of the salivary glands, ${ }^{24}$ (Table 2 ). The xeros- 
tomic individuals were 6.4 and 5.2 times more likely to give a positive response to questions about having too little saliva and having a dry mouth when eating, but they were 14 times more likely to state that their cheeks stuck to their teeth or dentures (Table 2). As such, these three questions might reliably identify individuals with salivary gland hypofunction.

Individuals with xerostomia in the morning reported having difficulty in chewing, in starting a swallow, and in swallowing (Table 2). This could influence their choice of foods, and, indeed, individuals with a complaint of xerostomia were significantly more likely to avoid crunchy foods such as carrots and sticky foods such as peanut butter (Table 2 ). Other investigators have shown that xerostomia can be associated with undernutrition among both institutionalized and independent-living older persons ${ }^{34}$ and that xerostomia is one of the common oral conditions associated with significant involuntary weight loss among frail older people. ${ }^{7}$ Our observations on food avoidances, albeit indirect measures of dietary intake, support the hypothesis that a complaint of xerostomia may contribute to undernutrition in older persons.

These adverse medical outcomes associated with complaints of xerostomia warrant efforts to prevent and treat this condition. More than $\mathbf{4 0 0}$ medications are believed to be xerogenic, ${ }^{19}$ which suggests that one approach to prevent or to reduce xerostomia would be to substitute a nonxerogenic medication for a xerogenic medication whenever the medical condition permits such an option.

We looked at the relationship between the 20 most frequently used medications and the various oral/dental parameters under investigation. The confounding effect of the use of more than one xerogenic medication, or of varying dosages of the medication and patient compliance, were not addressed. Nine medications could be associated significantly with either a complaint of xerostomia or with diminished salivary gland performance. Triazolam, amitriptyline, and sucralfate, which could be significantly associated with both a complaint of xerostomia and with a reduction in stimulated salivary flow, were the most xerogenic of these medications. Of these, amitriptyline and triazolam, which have been grouped by several authors with antipsychotic, hypnotic, and psychotropic medications, have frequently been associated with xerostomia. ${ }^{15,17,18,21-23,32,33,35,36}$ There is apparently little data that associates sucralfate with decreased salivary gland performance. ${ }^{21}$

Ipratropium bromide and triamcinolone acetonide, used as inhalants in the treatment of emphysema and asthma, were significantly associated with complaints of xerostomia and with the patients own assessment that they had too little saliva (Table 4). However, neither agent significantly affected stimulated salivary flow and perhaps, because of the mucosal dryness, there was a compensatory increase in the minor salivary gland output when ipratropium was used (Table 4). Oxybutynin and ibuprofen could be associated with complaints of xerostomia but not with any decrease in salivary gland performance. Fluoxetine, although used by only nine subjects, could be associated with a reduction in stimulated salivary flow. Previously we had found that fluoxetine significantly reduced stimulated salivary flow in young, bulimic women. ${ }^{37}$ This would suggest that the substitution of fluoxetine for any of the tricyclic antidepressants may not improve salivary flow.
When considering the relationship between drugs and salivary glands, it is necessary to recognize the difference between medications that cause the sensation of dryness, but which may have no effect on the salivary glands, and those medications that can actually inhibit or alter salivary secretions. ${ }^{21}$ Other investigators have noted that oral dryness does not reliably indicate decreased salivary output. ${ }^{21,27,38}$ With ipratropium bromide and triamcinolone acetonide, this difference was clearly observed as these topical agents caused dryness of the oral surfaces, yet had no discernible effect on salivary flow. In this case, the absence of an effect probably reflected that these topically delivered agents did not achieve systemic levels that could influence salivary secretion.

It was of interest to determine whether any of the twenty most frequently used medications could be associated with a history of food avoidances. Ipratropium could be associated with the avoidance of chewy and crunchy foods. This observation suggests that this topically applied agent was causing either a degree of dryness or a sense of dryness that made certain foods uncomfortable to eat, despite the fact that the salivary flow was not obviously reduced. Individuals who used amitriptyline were 7 times more likely to avoid chewy foods such as meat. Diphenhydramine, a putative xerogenic medication, for which we could find no association with a complaint of xerostomia or of a reduced salivary flow, was, however, associated with an avoidance of crunchy type foods. None of the medications associated with a reduction in salivary flow, with the exception of amitriptyline, could be associated with the avoidance of any types of food, suggesting that the sense of dryness, rather than a lack of saliva, was the most important consideration in the subject's food preferences. In the case of amitriptyline, there were also complaints of xerostomia, reinforcing the suggestion that xerostomia per se was the main determinant of food avoidances.

The present findings confirm other studies that show that complaints of xerostomia are common among older persons $^{10,11,15-18,21}$ and that these complaints can be associated with the use of one or more medications that are considered to be xerogenic. ${ }^{10,11,15-18,21}$ Specific medications were identified that appeared more likely to be associated with xerostomia than others. Of these, the topically applied ipratropium and triamcinolone, both inhalants used for bronchial dilation, and the systemic agents oxybutynin, triazolam, and amitriptyline, could be statistically associated with one or more complaints of xerostomia. Of these, only triazolam and amitriptyline could be associated with a reduced salivary flow.

\section{ACKNOWLEDGMENTS}

Carol Gerlach assisted in the preparation of this manuscript. Gary Hildebrandt and Katherine Curry assisted in the collection of dental data. Bonnie Hartsuff assisted in the statistical analysis.

\section{REFERENCES}

1. Geissler CA, Bates JF. The nutritional effects of tooth loss. Am J Clin Nutr 1984;39:478-489.

2. Shatenstein B. Tooth loss, mastication, and oral health in the elderly. J Am Diet Assoc 1986;86:86-87.

3. Howath CC. Chewing difficulty and dietary intake in the elderly. J Nutr Elderly 1989;9:17-24.

4. Hatton ER, Gogan CM, Hatton MN. Common oral conditions in the elderly. Am Fam Physician 1989;40:149-162.

5. Neissen LC, Jones JA. Oral health changes in the elderly: Their relationship to nutrition. Postgrad Med 1984;75:231-237. 
6. Miller AJ, Brunelle JA, Carlos JP et al. Oral health of United States adults. Bethesda, MD: National Institute of Health. DHHS Pub No.87-28681987.

7. Sullivan DH, Martin W, Flaxman N et al. Oral health problems and involuntary weight loss in a population of frail elderly. J Am Geriatr Soc 1993;41:725-731.

8. Sullivan DH, Patch GA, Walls RC et al. Impact of nutritional status on morbidity and mortality in a select population of geriatric patients. Am J Clin Nutr 1990;51:749-758.

9. Sullivan DH, Walls RC, Lipschitz DA. Protein-energy undernutrition and the risk of mortality within $1 \mathrm{y}$ of hospital discharge in a select population of geriatric patients. Am J Clin Nutr 1991:53:599-605.

10. Ben-Aryeh H, Miron D, Berdicevsky I et al. Xerostomia in the elderly: Prevalence, diagnosis, complications and treatment. Gerodontology 1985;4:7782.

11. Osterberg T, Birkhed $D$, Johansson $C$ et al. Longitudinal study of stimulated whole saliva in an elderly population. Scand J Dent Res 1992;100:340-345.

12. Sreebny LM, Valdini .A Xerostomia. A neglected symptom. Arch Intern Med 1987;147:1333-1337.

13. Mandel ID. Sialochemistry in diseases and clinical situations affecting salivary glands. CRC Crit Rev Clin Lab Sci 1980;12:321-366.

14. Dreizen S, Brown LR, Handler $S$ et al. Radiation-induced xerostomia in cancer patients. Cancer 1976;38:273-278.

15. Narhi TO, Meurman JH, Ainamo A et al. Association between salivary flow rate and the use of systemic medication among 76-, 81-, and 86-year-old inhabitants in Helsinki, Finland. J Dent Res 1992;71:1875-1880.

16. Osterberg T, Hedegard B, Sater G. Variation in dental health in 70-year-old men and women in Goteborg, Sweden. A cross-sectional epidemiological study including longitudinal and cohort effects. Swed Dent J 1984;8:29-48.

17. Johnson G, Barenthin I, Westphal P. Mouthdryness among patients in longterm hospitals. Gerodontology 1984;3:197-203.

18. Kreher JM, Graser GN, Handelman SL. The relationship of drug use to denture function and saliva flow rate in a geriatric population. J Prosthet Dent 1987;57:631-638.

19. Sreebny LM, Schwartz SS. A reference guide to drugs and dry mouth. Gerodontology 1986;5:75-99.

20. Rundegren J, van Dijken J, Mornstad $\mathrm{H}$ et al. Oral conditions in patients receiving long-term treatment with cyclic antidepressant drugs. Swed Dent J 1985;9:55-64.

21. Atkinson JC. Salivary gland dysfunction. Clin Geriatr Med 1992;8:499-511.
22. Sreebny LM, Valdini A, Yu A. Xerostomia. Part II: Relationship to nonoral symptoms, drugs, and disease. Oral Surg Oral Med Oral Pathol 1989;68:419-427.

23. Thorselius I, Emilson CG, Osterberg T. Salivary conditions and drug consumption in older age groups of elderly Swedish individuals. Gerodontics 1988:4:66-70.

24. Fox PC, Busch KA, Baum BJ. Subjective reports of xerostomia and objective measures of salivary gland performance. J Am Dent Assoc 1987;115:581584.

25. Fox PC, van der Ven PF, Sonies BS et al. Xerostomia: Evaluation of a symptom with increasing significance. J Am Dent Assoc 1985;110:519-525.

26. Shern RJ, Fox PC, Cain JL et al. A method for measuring the flow of saliva from the minor salivary glands. J Dent Res 1990;69:1146-1149.

27. Papas AS, Joshi A, MacDonald SL et al. Caries prevalence in xerostomic individuals. J Can Dent Assoc 1993;59:171-174.

28. Sreebny LM, Valdini A. Xerostomia. Part I. Relationship to other oral symptoms and salivary gland hypofunction. Oral Surg Oral Med Oral Pathol 1988;66:451-458.

29. Atkinson JC, Shiroky JB, Macynski A et al. The effects of furosemide on salivary secretions. Gerodontology 1989;16:23-28.

30. Schneyer LM. Source of resting total mixed saliva of man. J Appl Physiol 1956;9:79-81.

31. Dawes $\mathrm{C}$, Wood CM. The contribution of oral minor mucous gland secretions to the volume of whole saliva in man. Arch Oral Biol 1973;18:337342.

32. Persson RE, Izutsu KT, Truelove EL et al. Differences in salivary flow rates in elderly subjects using xerostomatic medications. Oral Surg Oral Med Oral Pathol 1991;72:42-46.

33. Saunders RH, Handelman SL. Effects of hyposalivatory medications on saliva flow rates and dental caries in adults aged 65 and older. Spec Care Dent 1992;12:116-121.

34. Rhodus NL, Brown J. The association of xerostomia and inadequate intake in older adults. J Am Diet Assoc 1990;90:1688-1692.

35. Wu AJ, Ship JA. A characterization of major salivary gland flow rates in the presence of medications and systemic diseases. Oral Surg Oral Med Oral Pathol 1993;76:301-306.

36. Winer JA, Bahn S. Loss of teeth with antidepressant drug therapy. Arch Gen Psychiatry 1967;16:239-240.

37. Bretz WA, Krahn DD, Drury M et al. Effects of fluoxetine on the oral environment of bulimics. Oral Microbol Immunol 1993;8:62-64.

38. Navazesh M. Xerostomia in the aged. Dent Clin North Am 1989;33:75-80. 